Silja Vöneky

\title{
Recht, Moral und Ethik
}

\section{Grundlagen und Grenzen demokratischer Legitimation für Ethikgremien}

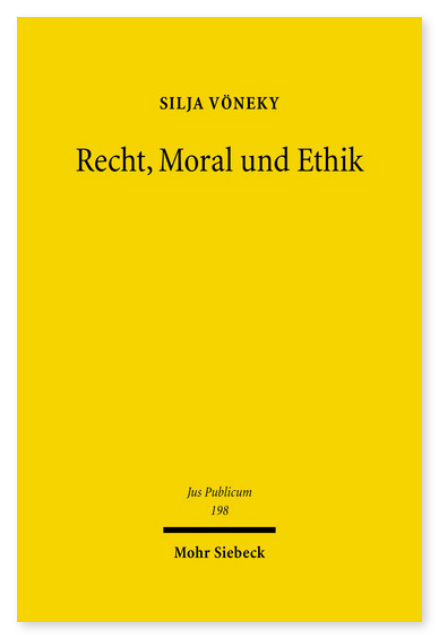

2010. XX, 699 Seiten. JusPubl 198

ISBN 978-3-16-151279-7

DOI 10.1628/978-3-16-151279-7

eBook PDF 159,00€

ISBN 978-3-16-150485-3

Leinen $159,00 €$
Gerade in Gesellschaften und Ordnungen, für die bestimmte Grade der Pluralität faktisch bestehen und normativ anerkannt sind, muss die Erörterung gemeinsamer Werte erfolgen, damit auf deren Basis Normsetzung und Normanwendung erfolgen können. Silja Vöneky zeigt, unter welchen Voraussetzungen Ethikgremien durch ihre Stellungnahmen in gerechtfertigter Weise einen Korridor ethischer Normsetzung aufzeigen können, der von Rechtsetzungs- und Entscheidungsorganen genutzt werden kann. Im Mittelpunkt ihrer Argumentation steht dabei das Verständnis der Demokratie der Bundesrepublik Deutschland als materiell-ethische. Nur solange und soweit die Gremien ihre Erörterungen in den Grenzen und auf der Grundlage der rechtlich maßgeblichen Prinzipien führen, kann verhindert werden, dass deren Ethisierung des Diskurses den vorrangig menschenrechtlich geprägten Rechtsdiskurs unzulässig untergräbt.

Silja Vöneky Geboren 1969; Studium der Rechtswissenschaft und Rechtsphilosophie an den Universitäten Freiburg, Bonn, Edinburgh (GB) und Heidelberg; 2000 Promotion; seit 2006 Leiterin einer Max-Planck-Forschungsgruppe zur »Demokratischen Legitimation ethischer Entscheidungen« in Heidelberg; 2009 Habilitation.

Jetzt bestellen:

https://mohrsiebeck.com/buch/recht-moral-und-ethik-9783161512797?no_cache=1

order@mohrsiebeck.com

Telefon: +49 (0)7071-923-17

Telefax: $+49(0) 7071-51104$ 